\title{
Accelerated Aging of Polymeric Composites in Laboratory Conditions
}

\section{Lenka Markovičová, Viera Zatkalíková, Alan Vaško}

Faculty of engineering, Department of materials engineering, University of Zilina, Univerzitna 8215/1, 010 26 Zilina, Slovakia, E-mail: lenka.markovicova@fstroj.uniza.sk

A "composite" is characterized as the comibation of two or more materials with diametrically different properties, which result into the creation of a new superior and unique material. This is the most commondefinition that holds true for all composites, however, more recently the term "composite" describes reinforced plastics. Polymers are used in every walk of life now-a-days. They are not even hundred years old, but play the significant role in every sector of life such as sports, defense, medicine, automotive, electrical, agricultural etc. In the beginning, polymers were considered as excellent insulators, but today also conductive polymers are available.. In general, polymers have good water resistance, but there are some polymers with good water absorbtion. Presented article deals with monitoring the changes in the mechanical properties of composites with polymer matrix. Composite has been formed from the PA (polyamide) matrix with glass fibers reinforcement. Mechanical properties, impact strength (Charpy) and micro-hardness (Vickers) have been evaluated on samples of the composite before and after the exposure of UV radiation.

Keywords: composite, artificial, aging, polymer, matrix, UV, radiaton

\section{Acknowledgement}

The research was supported partially by Scientific Grant Agency of Ministry of Education, Science and Sport of Slovak Republic and Slovak Academy of Science grant VEGA No. 1/0123/15 and by project KEGA No. 044ŽU-4/2014.

\section{References}

[1] Handbook of polymer testing. ed. Roger Brown, Marcel Dekker, New York 1999

[2] Standards STN EN ISO 4892 Plastics - Methods of exposure to laboratory light sources

[3] BORUVKA, M., NGAOWTHONG, Ch., CERMAN, J., LENFELD, P., BRDLIK, P. (2016). The Influence of Surface Modification Using Low-Pressure Plasma Treatment on PE-LLD/ $\alpha$-Cellulose Composite Properties. Manufacturing Technology, February 2016, Vol. 16, No. 1, p. 29-34

[4] VALÁŠEK, P. (2016). Short Sisal Fibers Reinforced Epoxy Resins: Tensile Strength. Manufacturing Technology, June 2016, Vol. 16, No. 3, p. 637-641

[5] MEISSNER, B., ZILVAR, V. (1987). Physics of Polymers. SNTL/ALFA, Praha 1987

[6] WEN, M., LUO, J. (2015). Study on Mechanical Properties of the Composite Resin Matrix Fiber Reinforced. Manufacturing Technology, April 2015, Vol. 15, No. 2, p. 243-249

[7] MALLICK, P.K.(1993). Fiber-Reinforced Composites: Materials, Manufacturing and Design, New York: Marcel Dekker, Inc., 1993 